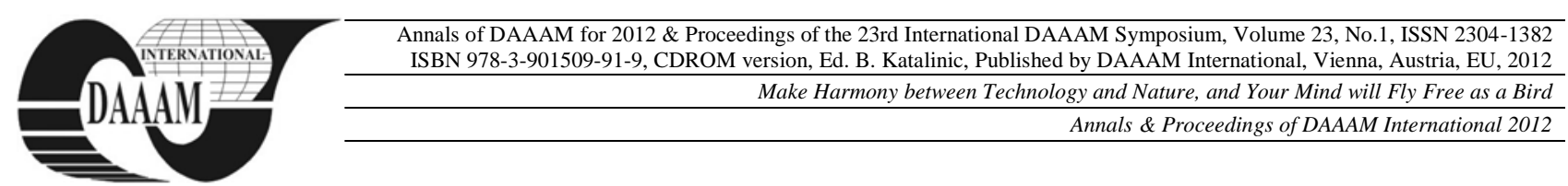

\title{
THE IMPORTANCE OF QUALITY CONTROL IN FIRMS' ACTIVITY
}

\author{
ACHIM, M[oise] I[oan] \& DRAGOLEA, L[arisa] - L[oredana]
}

\begin{abstract}
Among the function of quality one can notice the quality control in company activity which translates to quality control. This paper is meant to emphasize the importance of this activity in a company as well as the elements that imply its proper practice. Quality control 'functions' in close connection with quality, or, more precisely, with its existence. Without providing full practice of quality in a certain activity quality control cannot be warranted.
\end{abstract}

Keywords: control, quality management

\section{INTRODUCTION}

ISO 9000-2005 standard defines quality as "a degree to which a set of inherent characteristics fulfils requirements" (Andrei Octavian Paraschivescu, 2008:27).

Quality of a product or service is not determined only by its inherent characteristics and properties but as well as the degree in which satisfies the necessities expressed by the user or beneficiary as well as other necessities that are not expressed but which have to be fulfilled. In contractual instances necessities are expressed but in other circumstances the implicit needs have to be identified and defined.

Regarding this definition of quality the ISO 90002005 standard comprises a series of definitions regarding specific terminology. In this way, for a better understanding of the concept, the definition uses the term 'entity' which can be represented, for example, by an activity or a process, a product, an organization, a system, a person or a combination of the above.

\section{THE QUALITY CONCEPT}

Starting from the vast experience gained trough time and from deep quality researches, we may assume that this matter has been approached long ago, when those who were practicing the art of negotiation left their marks on the merchandise quality. They were trying to bring new products with better quality on the marketplace, without taking into account if they are materials, food, decorations and so. As the time passed by and the technology progressed, the quality concept has became an important factor for the products available on the marketplace.

Directly involved in this matter are the people and the existence of avanced technology - because without it we wouldn't be able to go trough this problem regarding quality. First of all, we're going to stop on the following aspect: the quality concept. From the performace point of view we may assume that this represents the achievement of some important key points for each firm which targets to become a marketplace leader. The quality concept is more like a introduction in quality, which includes: high, medium and low quality.

Once the product is on the marketplace, there are two new concepts:

- from the producer's point of view, the one who sells the products, the quality is medium or high.

- from the customer`s point of view, the quality is not always that good

The product quality represents the firm. Even if the devotion for quality starts from the company's management, which must handle the whole responsability for it, all the employees must be loyal to this improving process of quality. The staff are those who posses the sources of knowledge that can inspire innovating ideeas, the ones who are leading the whole development process.

Creating and implementing the ideas cannot be made in an unfriendly envivorment, in which this activities are not appreciated and supported and also, encouraged. To convince the employees how to play their roles in this improving process of quality, a lot of excitement and respect is required, from the firm`s management, for the staff's activities.

The importance of quality management ensues from at least the following considerations: firstly, for a unit, to achieve and to maintain the quality wanted by the client, in conditions of efficiency, represents a necessity for its existence. Reaching this desideratum is conditioned by the planned and efficient use of the human, material and financial resources. On the other hand, the client wants to trust the ability of the unit to supply the wanted quality and to maintain it. To earn this trust, the company must be able to prove that it has implemented an efficient quality system.

Beside the two mentioned aspects, the demands of society must be taken into account more and more now, these demands are materialized in regulations and restrictions which target the protection of the individual's life and health and the protection of the environment. 


\section{THE DIAGRAM OF THE THREE QUALITIES}

Differences occurring between the quality desired by the client, the designed quality and the fabrication quality make the circles of the three qualities not to overlap and creates deviation from concentricity. Complete satisfaction of the client corresponds to the area of intersection between all three elements pictured in the figure bellow by three circles: the designed quality, the fabrication quality and the quality desired by the client (figure 1).

Consequently, the mission is to improve each of the three qualities to make the three circles become concentric and reaching in this way the ideal quality and total satisfaction of the client

In this way despite all controls, measurements, weighting, analyses, checking etc. done during the final moment of production, in most of the times the client is the one who assesses the quality, accepting or rejecting the product.

\section{QUALITY CONTROL}

Quality control has the tendency of emphasizing the identification of deficiencies in a process. (Yoshio
Kondo, 2003:41).An organization must use all the practical methods for preventing, detecting and correcting the errors that appear in different stages of operation. For realizing a real quality control any of the variables that can affect quality have to be kept under control as these variables are the result of peoples' actions, of the nature of the materials or of the performance of the equipments.

Quality control is defined by BS 4778 Standard as: "the operational techniques and activities used for fulfilling the quality requirements"(Arcadie Hinescu, 2004:19). Quality control is meant to determine by measurements, observations, simulations, analyses the quality characteristics of a product on its entire duration of the fabrication process starting with raw materials and finishing with delivery (we can notice that the control stages from the production field have a correspondent in the commercial one.) The notion of control does not have to be identified with the inspection one.

While the inspection just records a nonconformity, product control is a stage that is done according to general specification (field standards, product internal norms) as well as to the specifications attributed to the product (approved pattern, size charts and technological specifications.) Quality control is part of the process of implementation of providing services including:

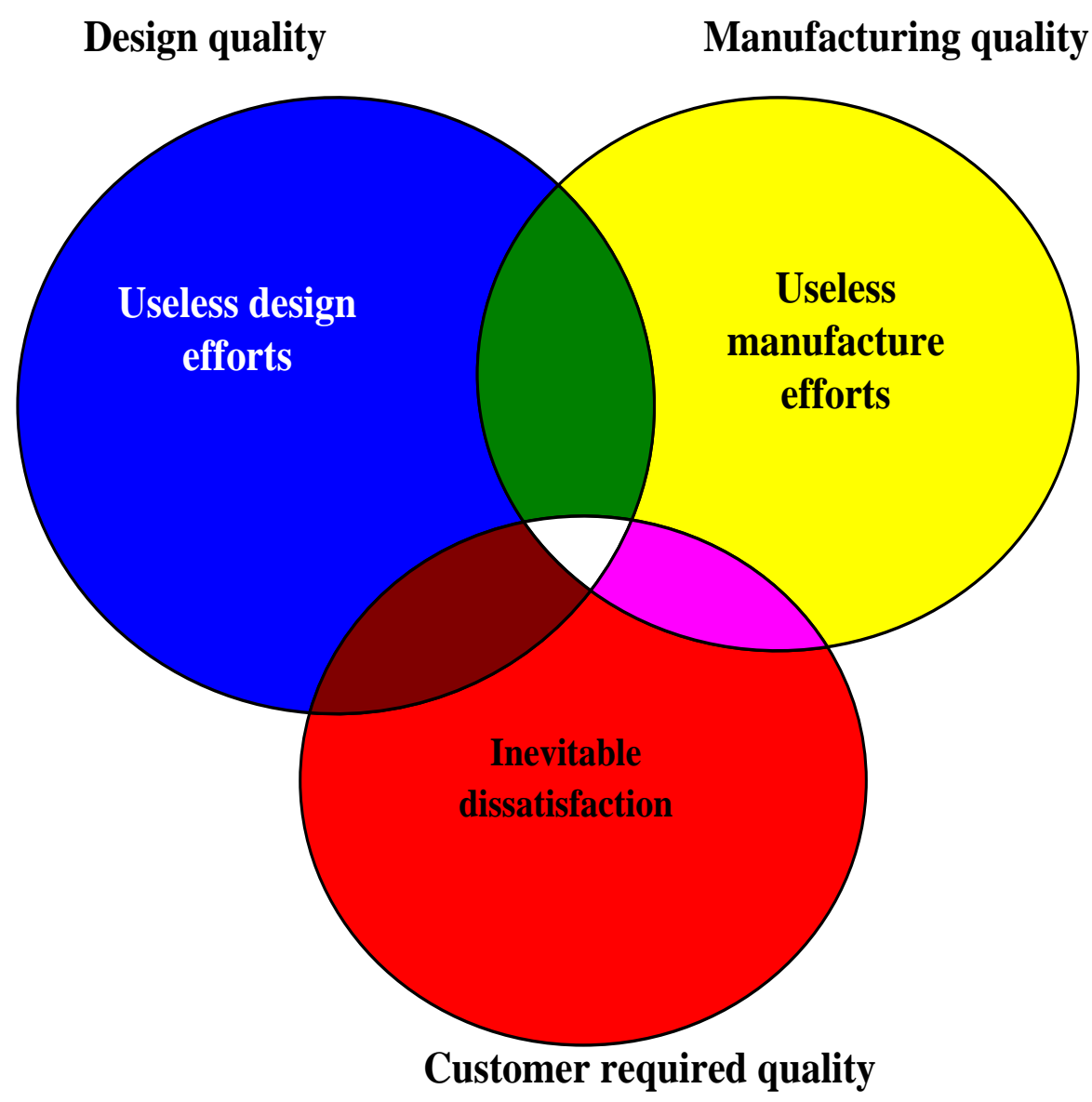

Fig. 1. The diagram of the three qualities Source: adjusted after Cănănău, Nicolae, Dima, Ovidiu, Gurău, Gheorghe, Gonzales Barajas, Ana (1998:17) Sisteme de asigurare a calităţii. Iasi: Junimea. 
Measurement and checking of key activities of the process in order to avoid apparition of unwanted tendencies and client dissatisfaction;

Self-control performed by the personnel responsible with providing services considered as part of the measuring process;

Final assessment of the interface with the client conducted by the supplier in order to keep up its own image of quality of the supplied service.

Quality control implies techniques with operational character that have as a goal both monitoring of a process and elimination of causes of faulty function. Quality control aims at fulfilling satisfaction conditions referring to quality.

\section{NECESSITY AND ROLE OF QUALITY CONTROL}

A held under control activity supposes some elements that can be decomposed and some other suppose results that can be quantified and measured. The things that cannot be measured can be planned and realized in accordance with some standards, checked, remedied or improved. The things that cannot be objectively checked raise questions and questions do not attract clients. Quality control must be present in the forerunning stages of the fabrication processes, during this process in the stage of control and delivery of final products. Moreover, it is necessary to follow the products and the way they react and behave in the stage of exploitation and usage.

\section{ESTABLISHING THE TYPE OF CONTROL}

There is a minimal control activity that records how work duties have been fulfilled, activity monitored by the manager on the immediate superior position. At organizational level though the control process is discontinuous meaning it is done through low key activities. Each activity has a certain aim no matter if it is set from the inside or the outside of the organization. This is why in projecting a control event the first thing to be established is the type of control to be performed.

If more control types intersect them there their convergence degree must be analyzed in order to avoid overlapping.

Employees are the ones representing the source of knowledge that can generate innovative ideas leading in this way the improvement process. Idea generation and implementation cannot be done in an environment in which these activities are not appreciated, stimulated and encouraged. For convincing the employees of the role they have to play in the process of quality improvement it needs a lot of enthusiasm from the side of the management and also showing respect towards the activity of the people. (Bogdan Rusu, 2001:90).

An important point to be reached is that the essence of quality can only be achieved when there is a balance between the enforced quality and the achieved quality. In fact this balance is the starting point of a company's internal rule for reaching quality parameters for products on the production line.

\section{THE RECEIPT CONTROL OF PRODUCTS SUPPLIES}

The products (raw materials, components, subassemblies) are checked in order to eliminate them from manufacturing if they can negatively influence the quality of the product. This product control has a relative static character, with a well determined role consisting of the evaluation of products, whether they are in a good state or not.

We can emphasise that the products which are in the business cycle are followed by a quality control.A varied range of methods correspond the quality control. There are two types of controls:

- assigned control, which aims to determine whether or not the characteristics fit the requirements. The products are appreciated according to this criterion as being proper or not.

- control by measurement.

These methods are adopted to the controled specific of the production, the time of quality characteristics, importance and implications of decision errors. In the TQM approach, the quality concept reffers to the acievement of all management objectives, defining the quality management as: "a company`s management system, focused on quality, based on the participation of every staff member, which targets a long-term success by meeting the client's needs, and also advantages for both the employees and company (Olaru M., et. al.).

\section{THE PLANNING PROCESS}

The planning process helps to identify the clients, their requirements and to develop a proper delivering service, in a way that the clients would be totally content. Indentifing the client implies an important procedure: learning his needs, defining the product and the process. The planning involves the following method: creating the new product, process, services or replacing them.

For a succesfull quality developing we must know the objectiv which needs to be achieved in order to improve the quality. Also, when improving the quality we must create a new performance level by specifying the deficiencies and the new performance. Quality planning, control and developement have an important role for the ultimate quality. In order to apply the management of ultimate quality, is necessary to create an infrastructure that is based on:

- $\quad$ application of a standard SR EN ISO 9000 series quality system through

- $\quad$ client-provider partnerships 
- full involvement of the organization

- measurement and Information

- $\quad$ education and training

\section{CONCLUSION}

Clients represent a force of influence of the competition because they can determine price drop, they can demand increased quality or more post-sale services and through this they can influence the market of a product. This is why it is very important to analyze the situation of the clients in order to know as much as possible about their behavior and to come meet their desires.

Clients' expectations depend on the experiences from the past and on the information they own regarding the company and the other competitor companies.

For the organization to be successfully ruled and functional it is necessary to be coordinated and controlled in a systematic and transparent manner. Success can be the result of implementation and maintaining of a management system that is designed to continually improve performance taking into consideration the needs of all interested parties.

Organizations depend on their clients and this is why they should understand current and future needs of their clients, they should satisfy client's requests and should be preoccupied with overcoming client's expectations. Quality control can prevent lots of problems that appear in normal development of any activity of a company.

People on all levels are the essence of the organization and their total involvement allows their abilities to be used in the maximum benefit of the organization. A certain result is reached more efficient when the afferent activities and resources are managed as a process.

The economical performances of the commercial society, the qualitative and quantitative characteristics of the activities incorporated by the society can be slightly marked by the chosen strategy for developing its activity.

\section{REFERENCES}

[1] Grabara, J.K., Bajdor, P., Okwiet, B., (2010), Center as a tool for logistics activities in support of the company on the example of SME's enterprise X, Polish Journal of Management Studies, 2, issue 1, p. 35-42

[2] Hinescu, A., (coord.), (2004), Managementul total al calitatíi, Editura Risoprint, Cluj-Napoca

[3] Ileana, I., Muntean, M., Kadar, M., Rotar, C., Risteiu, M., (2009), Decision support system built in fuzzy logic, Proceedings of the 6-th International Conference on Theory and Applications in Mathematics and Informatics - ICTAMI 2009, ISBN 1582-5389, Alba Iulia, Romania, September, 3-6

[4] Kondo, Y. (2003). Managementul total al calităţii-modelul japonez., Editura Niculescu, Bucureşti

[5] Moraru, R., Băbuţ, G., Cioca, LI (2011). Knowledge management applications in occupational risk assessment processes, Proceedings of the 17th International Conference „The Knowledge-Based Organization”, section: , pp. , Land Forces Academy Sibiu, Romania („Nicolae Bălcescu” Land Forces Academy Publishing House; ISSN 1843-6722)

[6] Olaru M., Lefter V. , Drăgulănescu N., Romcea L., (2000), Techniques and instruments used in Quality Management, Economică Publishing, Bucharest

[7] Paraschivescu, A.O., (2008). Managementul calităţii, Editura Tehnopress, Iaşi

[8] Paştiu, C., (2011). Marketing in industria usoara, Editura Altip, Alba Iulia, p.170-200

[9] Popescu, M., Paleriu, E. (2002). Managementul calitatii, Editura Infomarket

[10] Rusu, B., (2001), Managementul calităţíi totale în firmele mici şi mijlocii, Editura Economică, Bucureşti. 